\title{
Jointly Held Investment Options and Vertical Relationships
}

\author{
Dimitrios Zormpas ${ }^{1}$
}

Published online: 24 August 2020

(c) The Author(s) 2020

\begin{abstract}
We find the optimal time for exercising a jointly held investment option. When the input market is competitive, the investment can take place earlier, later, or exactly when the optimal investment threshold is reached depending on how the option holders interact and on the bargaining power distribution. When instead the input supplier has market power, the game-theoretic framework downstream is shown to be of secondary importance. The timing effect that is attributed to the vertical relationship is always prevailing, which dictates the inefficient postponement of the investment.
\end{abstract}

Keywords Investment analysis $\cdot$ Nash bargaining $\cdot$ Real options $\cdot$ Vertical relations

JEL Classification C61 · D92 · G30

\section{Introduction}

Innovation is an important factor for a company's success and a crucial explanation for observed differentials in performance (McGrath and Nerkar 2004). Consequently, a fundamental problem that a firm faces has to do with the decision to invest in a new product or technology. These managerial decisions are characterized by risky, irreversible and lumpy investments that are often beyond the resources of a single firm (Chesbrough and Schwartz 2007). As a result, an investment partner is frequently sought (Kogut 1991; Scott 1996). According to Quinn (2000), using partnerships "companies have lowered innovation costs and risks by $60 \%$ to $90 \%$, while similarly decreasing cycle time and leveraging their internal investments by tens to hundreds of times".

Investment partnerships might take the form of joint ventures, venture capital investments, strategic alliances, or mergers. Irrespective of the exact nature of the

Dimitrios Zormpas

dimitrios.zormpas@unibs.it

1 Department of Economics and Management, University of Brescia, C.da S. Chiara, 50,

25122 Brescia, Italy 
partnership, the reasons that motivate it are common: When joining forces with another firm, a potential investor anticipates financial returns and/or future growth opportunities. ${ }^{1}$

The real options approach is a standard framework for the analysis of such opportunities. It builds on the idea that the option to undertake an investment that is characterized by uncertainty and irreversibility is analogous to an American call option on a real asset. Hence, the potential investor needs to factor in that, at the time of the investment, he forgoes the option to reconsider the investment decision at some future time point when the uncertainty will be, naturally, partly resolved. ${ }^{2}$ This means that apart from the investment cost, there is also an opportunity cost that the investment needs to pay for.

The standard real options model does not account for investment partnerships. However, there is a growing body of papers that analyze investments that involve two or more parties that can generate a surplus by jointly exercising an investment option. In spite of the differences in their analyses, what these papers share is the assumption that the inputs that are required for the investment to take place are competitively priced.

The key originality of our work is as follows: We discuss the optimal exercise of a jointly held investment option and explicitly assume that the input supplier has market power. Our analysis evolves as follows: We first present the case where the input market is competitive and the investment option is held by a single party. This constitutes our standard of comparison. Then, we discuss an investment option that is jointly held by two parties. We assume that the two option holders first agree on how to share the surplus that is generated by the project and then one of them chooses the timing of the investment. The sharing rule is chosen, either cooperatively, using a Nash bargaining solution, or non-cooperatively.

In line with the extant literature we show that when the input market is competitive the investment can take place before, after, or exactly when the optimal investment threshold is reached. This depends on the way the two parties interact cooperatively or non-cooperatively and on the bargaining power distribution. When instead the input market is non-competitive, we show that, irrespective of the game theoretic framework downstream, the investment takes place inefficiently late.

The main message that the paper conveys is that, as soon as the completion of the investment depends on the provision of an input by an upstream firm with market power, the way that the two option holders interact (non-cooperatively versus Nash bargaining) is of secondary importance since the investment timing is always dictated by the presence of the input supplier. This result highlights the importance of the nature of the input market (competitive or non-competitive) when considering jointly held investment options.

The remainder of the paper is organized as follows. In Sect. 2 we present an overview of the related literature. In Sect. 3 we present the model set-up and demonstrate

\footnotetext{
1 See e.g., Martin (1994), Dushnitsky and Lenox (2005a), Smit and Trigeorgis (2006), Reuer and Tong (2007) and Vrande and Vanhaverbeke (2013).

2 See Dixit and Pindyck (1994) for an overview.
} 
the connections with previous work. In Sect. 4 we introduce an input supplier with market power, and Sect. 5 concludes.

\section{Overview of the Related Literature}

The real options approach has been used to study a variety of investment partnerships as, for instance: joint ventures (see, e.g., Kogut 1991; Li et al. 2008; Cvitanić et al. 2011; Banerjee et al. 2014; venture capital investments (see, e.g., Dushnitsky and Lenox 2005b; Vrande and Vanhaverbeke 2013; Lukas et al. 2016); and mergers and acquisitions (Folta and Miller 2002; Lambrecht 2004; Benson and Ziedonis 2009; Tong and Li 2011).

The most closely related work we have identified is in corporate finance and supply chain management: most notably, Cvitanić et al. (2011); Chen (2012); Lukas and Welling (2014); and Banerjee et al. (2014).

Cvitanić et al. (2011) discuss a joint venture between a large company and an entrepreneurial firm that consider the development of a new product. The two firms need to agree on the timing and on the terms of the investment. Chen (2012) models a two-echelon supply chain that consists of one supplier and one retailer. The two parties first negotiate over the capacity of the supply chain and then coordinate in determining the optimal timing of investing in it. Similarly, Lukas and Welling (2014) model the optimal timing of climate-friendly investments in a supply chain framework and enrich the contribution of Chen (2012) by adopting a non-cooperative game-theoretic setting. Last, Banerjee et al. (2014) develop a general framework that embeds contractual arrangements that are analyzed in the extant literature as its special cases.

Despite the differences in the adopted framework, what all these papers have in common is the assumption that the input that is required for the investment to take place is produced in-house, or, equivalently, is competitively priced. However, as highlighted by Billette de Villemeur et al. (2014), this is not necessarily true. The novelty of our work lies exactly in the analysis of the interaction between the option holders given the presence of an input supplier with market power.

There are numerous real-world examples that fit this setting. An example that is extensively discussed in the literature has to do with joint ventures in the pharmaceutical and biotechnology industries. Large firms with hefty budgets and large sales networks seek alliances with small entrepreneurial firms. At the same time, a small entrepreneurial firm will opt for a joint venture with a large firm if this means access to resources that are too costly to acquire or manufacture (see Cvitanić et al. 2011).

Joint ventures like these often depend on the purchase of a patent or some type of equipment from a specialized input provider with market power. For instance, Billette de Villemeur et al. (2014) discuss an investment in a plant that is dedicated to the production of vaccines. In the example that they present, the specialized equipment is a customized liquid nitrogen refrigeration unit. The cost of this piece of 
equipment represents $35-40 \%$ of the total plant construction cost and needs to be purchased by a firm with a market share of $80 \% .^{3}$

One can also think of large infrastructure projects where an upstream firm with market power is responsible for the provision of some basic infrastructure or input. For instance, this is the case in the oil and gas extraction industries. Joint ventures in the oil sector are common since they are used to share risk (see Kogut 1991). At the same time, the relevant input market is composed of companies that are providing the specialized infrastructure, equipment and know-how that is needed to explore for, and extract, crude oil and natural gas (see e.g. Gong 2018). In the same vein, Pennings (2017) refers to joint investments in a telecommunications network or a real-estate project. In this case a specialized construction company is responsible for the provision of an input e.g., a telecommunications network or a building that is tailored to the needs of the future user.

Large-scale climate-friendly investments also fit in this setting. According to Lukas and Welling (2014), large-scale green investments can depend on the participation of many firms even whole supply chains. At the same time, there is empirical evidence that suggests that, for instance, when it comes to the production of electricity from renewable energy sources, the input market can be highly concentrated (see, e.g., Pillai and McLaughlin 2013; Rothwell 2009; and references therein).

In all of these cases we are dealing with jointly held investment options that are dependent on the procurement of a piece of equipment or service from an input supplier with market power. Our analysis applies to investments with these characteristics.

\section{The Model}

In this section we begin with the description of the basic set-up, and then we make the connection with the extant literature that discusses a competitive input market. Table 1 summarizes the notation that the reader will come across in the following sections.

\subsection{The Basic Set-Up}

$A$ and $B$ hold jointly the option to operate in a final market. ${ }^{4}$ In order to do so, they need to invest in an indispensable input that is produced by an upstream firm $U$. The production cost of the input is $I>0$, and its price is chosen by $U$.

As soon as the investment takes place, the project starts generating a cash flow $y_{t}$ that fluctuates over time according to the following geometric Brownian motion:

\footnotetext{
3 See Billette de Villemeur et al. (2014, p. 119) for more details.

${ }^{4}$ For the rest of the paper we use male pronouns for $A$ and female pronouns for $B$.
} 


$$
\frac{d y_{t}}{y_{t}}=\alpha d t+\sigma d W_{t}, y_{0}=y
$$

where: $\alpha$ is the drift; $\sigma$ is the instantaneous volatility; and $d W_{t}$ is the standard increment of a Brownian motion. $A, B$, and $U$ are assumed to be risk-neutral with the risk-free interest rate denoted by $r>\alpha$. This assumption guarantees that the problem that we are studying is economically meaningful.

The operating value of the project at the generic time $t>0$ is: ${ }^{5}$

$$
E_{t}\left[\int_{t}^{\infty} y_{s} e^{-r(s-t)} d s\right]=\frac{y_{t}}{r-\alpha}
$$

Without loss of generality, we assume that $A$ is allocated with the right to exercise the option to invest. As for the sharing rule, we discuss both a non-cooperative setting in which $B$ is the party that is choosing how the project value $\frac{y_{t}}{r-\alpha}$ is shared, and a Nash bargaining solution in which $A$ and $B$ choose the sharing rule together. In either case, $B$ covers an exogenous share $\xi \in(0,1)$ of the investment cost and receives a share $\psi \in(0,1)$ of $\frac{y_{t}}{r-\alpha}$. A pays the rest of the cost and receives the rest of the operating value. ${ }^{6}$

\subsection{Optimal Timing When the Input Market is Competitive}

Since in this section the input market is by assumption competitive, the price and the production cost of the input coincide. This allows us to focus on the interaction between $A$ and $B$. In Sect. 3.2.1 we discuss the case where $A$ carries out the investment on his own. Then, in Sects. 3.2.2 and 3.2.3 we discuss an investment that requires investment from both $A$ and $B$.

\subsubsection{Solely Held Investment Option}

Suppose that the investment option is solely held by $A$. The standard net present value (NPV) rule suggests that it is optimal for $A$ to invest as soon as $y^{N P V}=I(r-\alpha)$ is reached. However, $A$ does not need to treat the investment opportunity as a nowor-never decision. On the contrary, he has the option to delay the investment decision and reconsider it at some point in the future when the uncertainty that is associated with the generated cash flow will be partly resolved.

The real options approach accounts explicitly for the option-like nature of $A$ 's choice. According to the real options approach, $A$ should delay the investment until the project's expected return is higher than the cost of the investment by a margin equal to the option value of further postponing the investment decision (see, e.g.,

\footnotetext{
${ }^{5}$ For simplicity we assume infinite operations.

${ }^{6}$ The creation of the investment opportunity is not attributed to either $A$ or $B$. In principle either $A$ or $B$ (or both of them) can be the originator(s) of the project. For relevant examples see Jørgensen et al. (2006), Cvitanić et al. (2011), Chen (2012), Lukas and Welling (2014) and Banerjee et al. (2014).
} 
Table 1 Notation

\begin{tabular}{|c|c|}
\hline$A, B, U$ & $A$ and $B$ are the investment option holders and $U$ is the input supplier \\
\hline$y_{t}$ & Cash flow generated by the project at time $t$ \\
\hline$d W_{t}$ & Standard increment of a Brownian motion \\
\hline$I$ & Input production cost (parameter) \\
\hline$\alpha$ & Drift of $y_{t}$ (parameter) \\
\hline$\sigma$ & Volatility of $y_{t}$ (parameter) \\
\hline$r$ & Risk-free interest rate (parameter) \\
\hline$\xi$ & $B$ 's cost share when the project is jointly held where $\xi \in(0,1)$ (parameter) \\
\hline$\eta_{j}$ & Bargaining power of $j \in\{A, B\}$ where $\eta_{A}+\eta_{B}=1$ (parameter) \\
\hline$\beta, \gamma$ & Roots of $\frac{1}{2} \sigma^{2} \zeta(\zeta-1)+\alpha \zeta-r=0$ where $\beta>1$ and $\gamma \leq 0$ \\
\hline$y^{*}$ & Investment threshold of a solely held project when the input market is competitive \\
\hline$y_{m}$ & Investment threshold of a solely held project when the input market is non-competitive \\
\hline $\bar{y}$ & $\begin{array}{l}\text { Investment threshold of a jointly held project when the project share is } \\
\text { non-cooperatively chosen and the input market is competitive }\end{array}$ \\
\hline $\bar{y}_{m}$ & $\begin{array}{l}\text { Investment threshold of a jointly held project when the project share is } \\
\text { non-cooperatively chosen and the input market is non-competitive }\end{array}$ \\
\hline$\hat{y}$ & $\begin{array}{l}\text { Investment threshold of a jointly held project when the project share is } \\
\text { cooperatively chosen and the input market is competitive }\end{array}$ \\
\hline$\hat{y}_{m}$ & $\begin{array}{l}\text { Investment threshold of a jointly held project when the project share is } \\
\text { cooperatively chosen and the input market is non-competitive }\end{array}$ \\
\hline$\psi$ & $B$ 's project share when the project is jointly held (choice variable) \\
\hline $\bar{\psi}$ & Non-cooperatively chosen project share when the input market is competitive \\
\hline $\bar{\psi}_{m}$ & Non-cooperatively chosen project share when the input market is non-competitive \\
\hline$\hat{\psi}$ & Cooperatively chosen project share when the input market is competitive \\
\hline$\hat{\psi}_{m}$ & Cooperatively chosen project share when the input market is non-competitive \\
\hline$p$ & Input price (choice variable) \\
\hline$p_{m}$ & Input price when the input market is non-competitive and the project is solely held \\
\hline $\bar{p}_{m}$ & $\begin{array}{l}\text { Input price when the input market is non-competitive, the project is jointly held } \\
\text { and the project share is chosen non-cooperatively }\end{array}$ \\
\hline$\hat{p}_{m}$ & $\begin{array}{l}\text { Input price when the input market is non-competitive, the project is jointly held } \\
\text { and the project share is chosen cooperatively }\end{array}$ \\
\hline
\end{tabular}

McDonald and Siegel 1986; Dixit and Pindyck 1994). ${ }^{7}$ Additionally, since in our set-up all of the information about the future evolution of Eq. (1) is embodied in $y_{t}$, there exists an optimal investment rule of the form: "Invest immediately if $y_{t}$ is at, or above, the critical threshold $y^{*}$ and wait otherwise". ${ }^{8}$ Given all of this, $A$ 's value of the option to invest is: ${ }^{9}$

\footnotetext{
${ }^{7}$ Leahy and Whited (1996), Guiso and Parigi (1999) and O’Brien et al. (2003) present empirical evidence supporting this argument.

${ }^{8}$ See Dixit et al. (1999) for more details.

9 See Dixit and Pindyck (1994, pp. 140-142).
} 


$$
F\left(y_{t}\right)=\max \left\{\frac{y_{t}}{r-\alpha}-I, \frac{1}{1+r d t} E_{t}\left[F\left(y_{t}+d y_{t}\right)\right]\right\}
$$

The difference $\frac{y_{t}}{r-\alpha}-I$ corresponds to the termination value of the investment: the net present value of the project if the investment takes place at time $t$. On the other hand, the term $\frac{1}{1+r d t} E_{t}\left[F\left(y_{t}+d y_{t}\right)\right]$ is the value that is associated with the postponement of the investment decision after $t$.

When the starting point of the cash flow is sufficiently low so that future, rather than immediate, investment is preferred when $y^{*}>y$ Eq. (3) reduces to $F\left(y_{t}\right)=\frac{1}{1+r d t} E_{t}\left[F\left(y_{t}+d y_{t}\right)\right]$, which can be written as: ${ }^{10}$

$$
\frac{1}{2} \sigma^{2} y^{2} F_{y y}+\alpha y F_{y}-r F=0 .
$$

This second-order homogenous differential equation needs to be solved subject to the following conditions:

$$
\begin{gathered}
F(0)=0 ; \\
F\left(y^{*}\right)=\frac{y^{*}}{r-\alpha}-I ; \\
F^{\prime}\left(y^{*}\right)=\frac{1}{r-\alpha}
\end{gathered}
$$

Condition (5) arises from the observation that if $y_{t}$ goes to zero, then the net present value of the project will become negative and consequently the value of the option to invest in it should be equal to zero. Conditions (6) and (7) come from the consideration of the optimal investment threshold $y^{*}$. Eq. (6) is the value matching condition and suggests that as soon as $A$ decides to exercise the investment option, he will receive exactly $\frac{y^{*}}{r-\alpha}-I$. Eq. (7) is a standard smooth pasting condition. Unless Eq. (7) holds at $y^{*}, A$ would do better by exercising the investment option at a different time point.

If we try $\Omega y_{t}^{\zeta}$ as a solution of Eq. (4), we obtain $\Omega y_{t}^{\zeta}\left(\frac{1}{2} \sigma^{2} \zeta(\zeta-1)+\alpha \zeta-r\right)=0$. $\Omega y_{t}^{\zeta}$ is a non-trivial solution of Eq. (4) provided that $\zeta$ is a root of the quadratic $\Phi(\zeta)=\frac{1}{2} \sigma^{2} \zeta(\zeta-1)+\alpha \zeta-r$. Since $\Phi(0)=-r \leq 0$ and $\Phi(1)=\alpha-r<0$, one root of $\Phi(\zeta)$ must be non-positive and one to the right of 1 . We call the former $\gamma$ and the latter $\quad \beta$. Solving $\frac{1}{2} \sigma^{2} \zeta(\zeta-1)+\alpha \zeta-r=0 \quad$ we obtain $\beta, \gamma=\frac{1}{2}-\frac{\alpha}{\sigma^{2}} \pm \sqrt{\left(\frac{\alpha}{\sigma^{2}}-\frac{1}{2}\right)^{2}+\frac{2 r}{\sigma^{2}}}$ where $\beta>1$ and $\gamma \leq 0$.

Since Eq. (4) is linear in $F$ and its derivatives, its general solution can be expressed as a linear combination of the two solutions. The general solution to Eq. (4) can be written as $F\left(y_{t}\right)=\Omega_{1} y_{t}^{\beta}+\Omega_{2} y_{t}^{\gamma}$ where $\beta>1, \gamma<0$ and $\Omega_{1}, \Omega_{2}$ are two

\footnotetext{
${ }^{10}$ If $y^{*} \leq y$ we have $F\left(y_{t}\right)=\frac{y_{t}}{r-\alpha}-I$, and the problem can be solved with the use of the standard NPV criterion.
} 
constants to be determined. For Eq. (5) to be satisfied we must have $\Omega_{2}=0$, whereas from Eq. (6) and Eq. (7) we obtain $\Omega_{1}=\left(\frac{y^{*}}{r-\alpha}-I\right) \frac{1}{y^{* \beta}}>0$ and:

$$
y^{*}=\frac{\beta}{\beta-1}(r-\alpha) I \text {. }
$$

Summing up, the value of the option to invest at $t=0$ is equal to:

$$
F(y)=\left(\frac{y^{*}}{r-\alpha}-I\right)\left(\frac{y}{y^{*}}\right)^{\beta} .
$$

The wedge $y^{*} / y^{N P V}=\beta /(\beta-1)>1$ reflects the impact of irreversibility and uncertainty in the investment timing. The intuition behind this result is as follows: When the investment option is exercised, there is an investment cost and an opportunity cost that the project needs to pay for. While the investment cost has to do with the mere realization of the project through the payment of $I$, the opportunity cost is related to the foregone option to postpone further the investment decision. In an evolving environment, time brings more information about the future prospects of a project. Thus, as long as the opportunity to invest remains available, a later decision can be a better one. Nevertheless, it is not sensible for a potential investor to abstain indefinitely from investing in a profitable project because an adverse turn of events cannot be ruled out. As demonstrated in Eq. (8), it is enough for conditions to become sufficiently favorable for the potential investor to exercise the investment option and not delay the investment further (Dixit 1992).

As for the properties of $\beta /(\beta-1)$, since $\partial \beta / \partial \alpha, \partial \beta / \partial \sigma,-\partial \beta / \partial r<0,{ }^{11}$ the markup $\beta /(\beta-1)$ is increasing in $\sigma$ and $\alpha$, whereas it is decreasing in $r$. Hence, the greater is the amount of uncertainty over the future values of $y_{t}$, the larger is the excess return $\beta /(\beta-1)$ that the potential investor will require before investing. Similarly, a potential investor prefers to wait more before investing in a very promising project since the expectations are higher. Last, a decrease in the interest rate discourages the investment. This happens because a lower $r$ means that the future is valued more by the potential investor. According to Dixit and Pindyck (1994, pp. 153-161) the markup $\beta /(\beta-1)$ can be substantial, on the order of 2 or 3 for many investment projects.

\subsubsection{Jointly Held Investment Option with a Non-cooperative Sharing Rule}

Suppose now that the completion of the project depends on $B$ who has to bear an exogenous share $\xi \in(0,1)$ of the investment cost. If we assume a non-cooperative setting, the interaction between the two parties evolves as follows: At $t=0, B$ credibly commits to contribute an exogenous share $\xi$ of the investment cost while claiming a share $\psi$ of the value of the project. Then, given the pair of $\xi$ and $\psi$, $A$ decides the timing of the investment. This sequence of moves is encountered in

${ }^{11}$ See Dixit and Pindyck (1994, p. 144) for a detailed discussion with regard to $\partial \beta / \partial \alpha, \partial \beta / \partial \sigma,-\partial \beta / \partial r<0$. 
various settings in the literature (see, e.g., Cvitanić et al. 2011; and Lukas and Welling 2014).

As is common with this type of games, we solve backwards starting with the time-deciding party $A$. The problem of $A$ is similar to the one presented in the previous subsection. The only difference is that here the net present value of the project is $(1-\psi) \frac{y_{t}}{r-\alpha}-(1-\xi) I$ instead of $\frac{y_{t}}{r-\alpha}-I$. Using similar arguments we find that the optimal investment threshold is $\bar{y}(\psi)=\frac{\beta}{\beta-1} \frac{1-\xi}{1-\psi}(r-\alpha) I=\frac{1-\xi}{1-\psi} y^{*}$ for any $\psi$ that $B$ might choose.

Given that $A$ will exercise the investment option as soon as $\bar{y}(\psi)$ is reached, $B$ needs to choose the compensation offer $\bar{\psi}$ that will maximize her expected net present value. The problem of $B$ can be written as:

$$
\max _{\psi \in(0,1)} E_{0}\left[\left(\psi \frac{\bar{y}(\psi)}{r-\alpha}-\xi I\right) e^{-r \bar{\tau}}\right]
$$

where $\bar{\tau}:=\inf \left\{t>0 \mid y_{t}=\bar{y}(\psi)\right\}$. In words, $B$ maximizes her expected net present value accounting for the fact that the investment will take place at $\bar{\tau}$ : as soon as $y_{t}$ reaches the investment threshold $\bar{y}(\psi)$. Expression (10) can alternatively be written as: $^{12}$

$$
\max _{\psi \in(0,1)}\left(\psi \frac{\bar{y}(\psi)}{r-\alpha}-\xi I\right)\left(\frac{y}{\bar{y}(\psi)}\right)^{\beta} .
$$

From the first-order condition we have $\bar{\psi}=\frac{\xi \beta-2 \xi+1}{\beta-\xi}$; and, consequently, $\bar{y}=\frac{\beta}{\beta-1} \frac{\beta-\xi}{\beta-1}(r-\alpha) I=\frac{\beta-\xi}{\beta-1} y^{*}>y^{*}$. In words, a jointly held investment option will be exercised, in expected terms, suboptimally later than a solely held one. This timing distortion is attributed to the fact that the time-deciding party $A$ receives only a share of the project since the rest is the compensation that $B$ claims for contributing $\xi$. Since the presence of $B$ reduces $A$ 's share of the surplus, $A$ requires the total surplus to be larger before investing and consequently chooses an investment threshold $\bar{y}$ which is higher than $y^{*}$.

Note that $\bar{\psi}>\xi: B$ always claims a share that is larger than the one that she contributing. Even in the extreme case where $\xi \rightarrow 0$ we have $\lim _{\xi \rightarrow 0} \bar{\psi}=\frac{1}{\beta}>0$. Since $A$ has no say in the choice of how the project is shared, $B$ claims a positive share irrespective of the magnitude of her contribution. As we will see in the next section this is not the case when $A$ and $B$ bargain over $\psi$ and $A$ has some bargaining power.

Summing up:

Proposition 1 When the input market is competitive and the sharing rule is chosen by $B$, the optimal investment threshold is $\bar{y}=\frac{\beta-\xi}{\beta-1} y^{*}>y^{*}$ : the project takes place inefficiently late.

\footnotetext{
12 One can easily show that $E_{0}\left[e^{-r \bar{\tau}}\right]=\left(\frac{y}{\bar{y}(\psi)}\right)^{p}$. See Lukas and Welling (2014, p. 452) and Dixit and Pindyck (1994, pp. 315-316).
} 


\subsubsection{Jointly Held Investment Option with a Nash Bargaining Sharing Rule}

One could easily think of a situation where $A$ and $B$ choose the terms of the deal together. For instance, $A$ can be a wealth-constrained entrepreneurial firm and $B$ a venture capitalist. Alternatively, $A$ and $B$ can be two firms that have the option to start a joint venture (see Jørgensen et al. 2006).

In the following, in line with Banerjee et al. (2014), we assume that $A$ and $B$ choose $\psi$ as an outcome of Nash bargaining and then $A$ decides the investment threshold. The problem for $A$ remains unchanged since, once the sharing rule is set, $A$ 's option to delay the investment is still alive. Consequently, $A$ 's reaction function is: $\hat{y}(\psi)=\bar{y}(\psi)=\frac{1-\xi}{1-\psi} y^{*}$. As for the sharing rule, $A$ and $B$ bargain over $\psi$ anticipating that $A$ will invest as soon as $\hat{y}(\psi)$ is reached.

The Nash bargaining problem can be written as

$$
\max _{\psi \in(0,1)} E_{0}\left[\left(\psi \frac{\hat{y}(\psi)}{r-\alpha}-\xi I\right)^{\eta_{B}}\left((1-\psi) \frac{\hat{y}(\psi)}{r-\alpha}-(1-\xi) I\right)^{\eta_{A}} e^{-r \hat{\tau}}\right],
$$

where: $\eta_{B} \in[0,1]$ represents the bargaining power of $B ; \eta_{A}=1-\eta_{B}$ represents the bargaining power of $A$; and $\hat{\tau}:=\inf \left\{t>0 \mid y_{t}=\hat{y}(\psi)\right\}$ is the first time point at which $y_{t}$ reaches the threshold $\hat{y}(\psi) .{ }^{13}$ In words: The two parties choose the share $\psi$ that maximizes the conditional expectation of the product of their properly weighted net present values, accounting for the fact that the investment takes place as soon as $\hat{y}(\psi)$ is reached. Note that the expression (12) is reminiscent of the expression (10). In fact, the two coincide when $\eta_{B}=1$ : when $B$ has all of the bargaining power.

Using similar arguments, we can rewrite (12) as:

$$
\max _{\psi \in(0,1)}\left(\psi \frac{\hat{y}(\psi)}{r-\alpha}-\xi I\right)^{\eta_{B}}\left((1-\psi) \frac{\hat{y}(\psi)}{r-\alpha}-(1-\xi) I\right)^{1-\eta_{B}}\left(\frac{y}{\hat{y}(\psi)}\right)^{\beta} .
$$

From the first-order condition we obtain $\hat{\psi}=\frac{\eta_{B}(1-\xi)+\xi(\beta-1)}{\beta-\xi}$; and, consequently, the investment threshold is $\hat{y}=\frac{\beta-\xi}{\beta-\eta_{B}} y^{*}$. ${ }^{14}$

Both $\hat{\psi}$ and $\hat{y}$ increase in $\eta_{B}$. The positivity of $\partial \hat{\psi} / \partial \eta_{B}$ is straightforward. It only makes sense that an investment partner with high bargaining power claims a higher compensation share. $\hat{\psi}$ can be as low as $\frac{\xi(\beta-1)}{\beta-\xi}$ when $\eta_{B}=0$ and as high as $\bar{\psi}$ when $\eta_{B}=1$. Since $\frac{\xi(\beta-1)}{\beta-\xi}<\xi<\bar{\psi}$, there must be some $\eta_{B}$ between 0 and 1 for which $\hat{\psi}$ becomes equal to $\xi$. Comparing $\hat{\psi}$ and $\xi$ we find that $\hat{\psi}=\xi$ when $\eta_{B}=\xi$.

As for the positivity of $\partial \hat{y} / \partial \eta_{B}$, the effect of $\eta_{B}$ on the investment threshold $\hat{y}$ passes through $\hat{\psi}$. An increase in the compensation share results in an increase in the investment threshold since $\partial \hat{y}(\psi) / \partial \psi>0$ where, as we have seen above, $\hat{y}(\psi)=\frac{1-\xi}{1-\psi} y^{*}$. At the same time, we have $\partial \hat{\psi} / \partial \eta_{B}>0$. Combining the two, we see that when $B$ has a lot of bargaining power, the share that she claims is high. $A$

13 As in Banerjee et al. (2014), we assume that the bargaining power distribution is exogenous.

14 Note that, as expected, we have $\hat{\psi}=\bar{\psi}$ and $\hat{y}=\bar{y}$ when $\eta_{B}=1$. 
accounts for this and in order to secure a sufficiently large payoff $(1-\hat{\psi}) \frac{\hat{y}}{r-\alpha}$ decides to delay the investment by choosing a high $\hat{y}$. On the contrary, if $\eta_{B}$ happens to be low, this will be reflected in a low $\hat{\psi}$. In this case, $A$ will be able to secure a sufficiently large payoff $(1-\hat{\psi}) \frac{\hat{y}}{r-\alpha}$ without waiting too long.

In the special case where $\hat{\psi}=\xi$ and, consequently, $1-\hat{\psi}=1-\xi$, we have $\hat{y}=y^{*}$. In this case, it is as if the two parties are not sharing separately the project's investment cost and operating value but the project as a whole. $A$ chooses $\arg \max _{\omega}\left((1-\psi) \frac{\omega}{r-\alpha}-(1-\xi) I\right)\left(\frac{y}{\omega}\right)^{\beta}$ which thanks to $\hat{\psi}=\xi$ is equal to $\arg \max _{\omega}\left(\frac{\omega}{r-\alpha}-I\right)\left(\frac{y}{\omega}\right)^{\beta}=y^{*}$ : the investment threshold that maximizes the value of the option to invest in the project.

Given that under $\eta_{B}=\xi$ we have $\hat{\psi}=\xi$ and consequently $\hat{y}=y^{*}$, and keeping in mind that $\hat{y}$ is increasing in $\eta_{B}$, one can easily see that $\hat{y}>y^{*}$ when $\eta_{B}>\xi$ : $\eta_{A}<1-\xi$ and $\hat{y}<y^{*}$ when $\eta_{B}<\xi: \eta_{A}>1-\xi$. The intuition is as follows: When the bargaining power of the time-deciding party is low $\left(\eta_{A}<1-\xi\right)$, he manages to claim a small project share $1-\hat{\psi}$. In order to remunerate for the small $1-\hat{\psi}$, $A$ chooses a higher investment threshold $\left(\hat{y}>y^{*}\right)$. The opposite happens when the bargaining power of the time-deciding party is high since in that case the large $1-\hat{\psi}$ allows for an earlier investment since what is lost in terms of project size $(\hat{y} /(r-\alpha))$ is remunerated in terms of project share $(1-\hat{\psi}) .{ }^{15}$

Summing up:

Proposition 2 When the input market is competitive and the two parties bargain over the sharing rule, the equilibrium threshold is $\hat{y}=\frac{\beta-\xi}{\beta-\eta_{B}} y^{*}$ : The investment takes place inefficiently late (early) when $\eta_{B}>\xi\left(\eta_{B}<\xi\right)$. The optimal investment threshold $y^{*}$ is obtained if $\eta_{B}=\xi$.

\section{Optimal Timing When the Input Market is Non-competitive}

Suppose now that $U$ has market power. In the following we analyze how the results of the previous section change under this assumption.

\subsection{Solely Held Investment Option When U has Market Power}

As in Sect. 3.2, we start discussing the case where the investment option is solely held by $A$. This will allow us to isolate the effect of a non-competitive input market

\footnotetext{
15 While here we assume that the two parties bargain over the ownership stake that $B$ will receive, one can also think of a compensation offer that is composed of both an ownership stake and a cash transfer. Banerjee et al. (2014) prove that when only cash transfers are used, the investment threshold turns out to be larger, or at most, equal to the optimal one. This is exactly what we find when $\eta_{B} \geq \xi$. They also prove that when a combination of cash transfers and ownership stakes is used, the optimal investment threshold is reached. This is what we find when $\eta_{B}=\xi$. Obviously, our assumption of a compensation offer with an ownership stake as its only ingredient, comes at no loss of generality.
} 
on the investment timing. Since the input market is non-competitive, the net present value of the investment project is not $\frac{y_{t}}{r-\alpha}-I$, as in Sect. 3.2.1, but $\frac{y_{t}}{r-\alpha}-p$, where $p$ is the input price chosen by $U$. Apart from this, the problem for $A$ remains identical to the one presented in Sect. 3.2.1. Solving we obtain $y_{m}(p)=\frac{\beta}{\beta-1}(r-\alpha) p .{ }^{16}$ The only difference between $y_{m}(p)$ and $y^{*}$ is the price of the input: $I$ when the input market is competitive and $p$ when it is not. As for the input supplier, in line with Billette de Villemeur et al. (2014), we assume that $U$ cannot observe the magnitude of $y_{t}$ at any time point but can observe the structural parameters of Eq. (1) and, thanks to this, can infer the investment timing that is chosen by the potential investor downstream. The input price is assumed to be chosen at time $t=0$ remaining constant thereafter. $^{17}$

$U$ chooses the $p$ that maximizes its expected net present value at the time of the investment. The problem of $U$ can be written as:

$$
\max _{p} E_{0}\left[(p-I) e^{-r \tau_{m}}\right]
$$

where $\tau_{m}:=\inf \left\{t>0 \mid y_{t}=y_{m}(p)\right\}$ is the first time point where $y_{t}$ reaches $y_{m}(p)$. Using similar arguments as in the previous subsection, we can rewrite (14) as:

$$
\max _{p}(p-I)\left(\frac{y}{y_{m}(p)}\right)^{\beta} .
$$

From the first-order condition we find that the optimal input price is equal to $p_{m}=\frac{\beta}{\beta-1} I$ which in turn implies $y_{m}=\frac{\beta}{\beta-1} y^{*}$. There are two important points to be made here: First, when the input market is non-competitive the input is (as expected) more expensive: $p_{m}>I$. Second, a more expensive input results in an investment that is further postponed $\left(y_{m}>y^{*}\right)$. As Billette de Villemeur et al. (2014) point out, this is a dynamic analog to the well-known static effect of double marginalization and can occur whenever an input supplier with market power distorts the cost of the input.

The fact that $p_{m} / I$ is equal to $\beta /(\beta-1)$ a quantity that we first encountered in Sect. 3.2.1 where we study the optimal exercise of a solely held investment option under a competitive input market is not a coincidence. When choosing the price of its output, $U$ accounts for its demand, which is captured by $A$ 's investment threshold $y_{m}(p)=\frac{\beta}{\beta-1}(r-\alpha) p$. A high $p$ will increase the profit $p-I$ but will result in the postponement of the investment by increasing the investment threshold $y_{m}(p)$. Instead, a low $p$ will reduce the profit $p-I$ but will also result in a shorter waiting

\footnotetext{
16 The subscript $m$ stands for "market power".

17 Billette de Villemeur et al. (2014) show that if the upstream firm can observe the realizations of $y_{t}$ over time, then it can dictate the optimal investment threshold $y^{*}$ by choosing an appropriate pricing rule instead of a fixed price. In this case, $U$ would be able to appropriate all of the benefits above the downstream firms' reservation value. In our analysis we abstain from the consideration of this pricing alternative because the assumption of an upstream firm that can verifiably observe the realizations of $y_{t}$ seems to us rather heroic. On the contrary, assuming that $U$ has just some basic information about the diffusion of $y_{t}$ seems more realistic.
} 
period. Solving problem (15) we find that it is optimal for $U$ to choose a price $\beta /(\beta-1)$ times higher than $I$. This happens because the demand for $U$ 's component is exclusively coupled with a single investment project downstream and, as a result, the same rules will govern the decisions of both the potential investor $A$ and the upstream supplier $U$. As in Sect. 3.2.1 where $A$ invests as soon as $y_{t}$ becomes $\beta /(\beta-1)$ times higher than $y^{N P V}$, here $U$ chooses a $p$ that at the time of the investment is $\beta /(\beta-1)$ times higher than $I$.

\subsection{Jointly Held Investment Option with a Non-cooperative Sharing Rule When $U$ has Market Power}

Suppose now that the project is jointly held by $A$ and $B$. As in Sect. 3.2.2, $B$ claims a project share $\psi$ and $A$ decides the timing of the investment, given $\psi$.

The problem of $A$ is similar to the one that he needs to solve when the project is solely held. The only difference is that now the net present value is $(1-\psi) \frac{y_{t}}{r-\alpha}-(1-\xi) p$ instead of $\frac{y_{t}}{r-\alpha}-p$. Solving the corresponding maximization problem ${ }^{r-\alpha}$ we obtain $\bar{y}_{m}(\psi, p)=\frac{\beta}{\beta-1} \frac{1-\xi}{1-\psi}(r-\alpha) p$, which is similar to $\bar{y}(\psi)=\frac{\beta}{\beta-1} \frac{1-\xi}{1-\psi}(r-\alpha) I$ that we derived in Sect. 3.2.2.

Given that $A$ will exercise the investment option as soon as $\bar{y}_{m}(\psi, p)$ is reached, $B$ needs to choose the compensation offer $\bar{\psi}_{m}$ that will maximize her expected net present value. More precisely, the problem of $B$ is: ${ }^{18}$

$$
\max _{\psi \in(0,1)}\left(\psi \frac{\bar{y}_{m}(\psi, p)}{r-\alpha}-\xi p\right)\left(\frac{y}{\bar{y}_{m}(\psi, p)}\right)^{\beta}
$$

which yields $\bar{\psi}_{m}=\bar{\psi}=\frac{\xi \beta-2 \xi+1}{\beta-\xi} \cdot{ }^{19}$ Given the investment threshold that is chosen by $A$ and the sharing rule that is chosen by $B$, the optimal input price $\bar{p}_{m}$ solves the following problem: ${ }^{20}$

$$
\max _{p}(p-I)\left(\frac{y}{\bar{y}_{m}(p)}\right)^{\beta} .
$$

Solving we find that the optimal input price is equal to $\bar{p}_{m}=\frac{\beta}{\beta-1} I$, which in turn implies:

$$
\bar{y}_{m}=\frac{\beta}{\beta-1} \frac{\beta-\xi}{\beta-1} y^{*} .
$$

\footnotetext{
18 The derivation of the objective function in (16) is similar to the derivation of the objective function in (11).

${ }^{19}$ Note that the equality $\bar{\psi}_{m}=\bar{\psi}$ suggests that the presence/absence of $U$ does not affect the magnitude of the optimal $\psi$. This has to do with the fact that $A$ and $B$ share the investment cost no matter if it is $I$ or $p$.

${ }^{20}$ The derivation of the objective function in (17) is similar to the derivation of the objective function in (15).
} 
Note that $\bar{y}_{m}>\bar{y}>y^{*}$. This inequality is the result of two complementary forces: The first is attributed to the interaction between the holders of the investment option, $A$ and $B$, which is captured by the term $(\beta-\xi) /(\beta-1)>1$, that appears both in $\bar{y}_{m}$ and in $\bar{y}$. The second is attributed to the market power of $U$, which is captured by the term $\beta /(\beta-1)>1$ that appears both in $\bar{y}_{m}$ and in $y_{m}$. This leads to the following proposition:

Proposition 3 When $U$ has market power and the sharing rule is chosen by $B$, the optimal investment threshold is $\bar{y}_{m}>\bar{y}$. This inequality suggests that the time distortion that is attributed to the market power of $U$ complements the time distortion that is attributed to the interaction between $A$ and $B$ resulting in the further postponement of the investment.

\subsection{Jointly Held Investment Option with a Nash Bargaining Sharing Rule When $U$ has Market Power}

As in Sect. 3.2.3 we now discuss the case where $A$ and $B$ determine the sharing rule as an outcome of Nash bargaining. The problem of $A$ is similar to the one presented in the previous subsection since, once the sharing rule is set, $A$ 's option to delay the investment is still alive. Consequently, the investment threshold that is chosen by $A$ remains the same: $\hat{y}_{m}(\psi, p)=\bar{y}_{m}(\psi, p)=\frac{\beta}{\beta-1} \frac{1-\xi}{1-\psi}(r-\alpha) p$.

As for the sharing rule, $A$ and $B$ bargain over $\psi$ anticipating that $A$ will invest as soon as $\hat{y}_{m}(\psi, p)$ is reached: ${ }^{21}$

$$
\begin{aligned}
& \max _{\psi \in(0,1)}\left(\psi \frac{\hat{y}_{m}(\psi, p)}{r-\alpha}-\xi p\right)^{\eta_{B}}\left((1-\psi) \frac{\hat{y}_{m}(\psi, p)}{r-\alpha}-(1-\xi) p\right)^{1-\eta_{B}} \\
& \left(\frac{y}{\hat{y}_{m}(\psi, p)}\right)^{\beta}
\end{aligned}
$$

From the first-order condition we obtain $\hat{\psi}_{m}=\hat{\psi}=\frac{\eta_{B}(1-\xi)+\xi(\beta-1)}{\beta-\xi}$. ${ }^{22}$ From the Sect. 3.2.3 we know that $\hat{\psi}_{m}$ is an increasing function of $\eta_{B}$, which becomes equal to $\xi$ when $\eta_{B}=\xi$. Last, given the investment threshold that is chosen by $A$ and the sharing rule that is chosen by both $A$ and $B, U$ chooses the optimal input price, solving: ${ }^{23}$

$$
\max _{p}(p-I)\left(\frac{y}{\hat{y}_{m}(p)}\right)^{\beta} .
$$

\footnotetext{
${ }^{21}$ The derivation of the objective function in (19) is similar to the derivation of the objective function in (13).

${ }^{22}$ This is analogous to the equality $\bar{\psi}_{m}=\bar{\psi}$.

23 The derivation of the objective function in (20) is similar to the derivation of the objective function in (15).
} 
From the first-order condition we obtain $\hat{p}_{m}=\frac{\beta}{\beta-1} I$ which, ${ }^{24}$ in addition to $\hat{\psi}_{m}=\hat{\psi}$, results in:

$$
\hat{y}_{m}=\frac{\beta}{\beta-1} \frac{\beta-\xi}{\beta-\eta_{B}} y^{*} .
$$

Proposition 4 When $U$ has market power and A and B bargain over the sharing rule, the equilibrium investment threshold is $\hat{y}_{m}>y^{*}$. This inequality suggests that, irrespective of the magnitude of $\xi$ and $\eta_{B}$, the investment takes place inefficiently late.

Note that, contrary to $\hat{y}$ that can be larger, smaller, or exactly equal to $y^{*}$, the investment threshold $\hat{y}_{m}$ is strictly larger than $y^{*}$ irrespective of the magnitude of $\eta_{B} \in[0,1]$ and $\xi \in(0,1)$. This means that when $A$ and $B$ choose the sharing rule cooperatively, the nature of the input market competitive or non-competitive determines whether it is possible for the investment to take place at, or before, $y^{*}$ or not.

Additionally, one can see that when $\xi<\eta_{B}$, the inequality $\hat{y}_{m}>y^{*}$ is the result of two complementary forces. On the one hand, the relatively high bargaining power of $B\left(\xi<\eta_{B}\right)$ is reflected in a large project share for her $\left(\hat{\psi}_{m}\right)$ and a small project share for $A\left(1-\hat{\psi}_{m}\right)$. Since $A$ is set to receive a small share of the project, he chooses to delay the investment until a sufficiently high investment threshold $\hat{y}_{m}$ is reached. This intention to wait more is reflected in $(\beta-\xi) /\left(\beta-\eta_{B}\right)>1$ that appears in Eq. (21). On the other hand, the high investment cost $\left(\hat{p}_{m}>I\right)$ favors the even further postponement of the investment and this is reflected in $\beta /(\beta-1)>1$ appearing in Eq. (21).

On the contrary, when $\xi \geq \eta_{B}$, the inequality $\hat{y}_{m}>y^{*}$ is the result of two opposing forces. One is again related to the presence of $U$ who is distorting the price. The other has to do with $A$ who is thanks to the relatively low bargaining power of $B\left(\xi \geq \eta_{B}\right)$ set to receive a relatively large cash flow share $1-\hat{\psi}_{m}$, and this makes him willing to avoid delaying the investment. This is reflected in the term $(\beta-\xi) /\left(\beta-\eta_{B}\right) \leq 1$ that appears in Eq. (21).

Nevertheless, $A$ 's willingness to avoid delaying the investment will never neutralize the delaying effect related to the presence of $U$ that is captured by $\beta /(\beta-1)>1$. The reason is that while $A$ chooses the investment threshold on his own, he still needs to bargain with $B$ when it comes to the choice of how the project value should be shared. For $\hat{y}_{m}(\psi)=y^{*}$ to be the case, the bargaining between $A$ and $B$ needs to result in a $\psi$ that is equal to $(\beta \xi-1) /(\beta-1)$. However, $\hat{\psi}_{m}$ is always larger than $(\beta \xi-1) /(\beta-1)$. Even in the extreme case where $B$ has no bargaining power $\left(\eta_{B}=0\right), \hat{\psi}_{m}$ is equal to $\xi(\beta-1) /(\beta-\xi)$, which is larger than $(\beta \xi-1) /(\beta-1)$ for any $\xi \in(0,1)$.

The investment threshold $\hat{y}_{m}$ approaches the optimal investment threshold $y^{*}$ only when $\eta_{B}=0$ and $\xi \rightarrow 1$. In this case, the time-deciding party $A$ is basically

${ }^{24}$ Note that $\hat{p}_{m}=\bar{p}_{m}=p_{m}$ which means that $U$ is indifferent to the way that $A$ and $B$ interact. 
participating in a costless project since the investment partner $B$ will have to pay almost all of the investment $\operatorname{cost}(\xi \rightarrow 1)$ as soon as the investment threshold that is dictated by $A$ is reached. Notably, $\lim _{\xi \rightarrow 1} \hat{\psi}_{m}\left(\eta_{B}=0\right)=1$ : In spite of $B$ 's lack of bargaining power, she manages to claim a project share that approaches $100 \%$ when $\xi \rightarrow 1$. While this might seem counterintuitive, one needs to account for the fact that in this case $A$ is investing in an almost costless project whereas $B$ has to cover almost all of the investment cost on her own. $A$ will not object to a "free lunch", no matter how small, whereas $B$ will claim the highest return that she can get. In this case the project is basically solely held by $B$ since she is paying almost all of the cost and she is claiming almost all of the generated value. $A$ is choosing the optimal timing for a project that is costless but results in a negligible return. In fact, $A$ 's investment option value $\left(\left(1-\hat{\psi}_{m}\right) \frac{\hat{y}_{m}}{r-\alpha}-(1-\xi) I\right)\left(\frac{y}{\hat{y}_{m}}\right)^{\beta}$ tends to zero for $\hat{\psi}_{m} \rightarrow 1$ and $\xi \rightarrow 1$ even if $\hat{y}_{m} \rightarrow y^{*}$.

\section{Discussion and Conclusions}

This work contributes to a growing body of papers that analyze the optimal exercise of jointly held investment options. The extant literature focuses on the interaction between the option holders discussing a variety of decision-making frameworks and the sequences of moves. An assumption that is ubiquitous in this literature is that the input market is competitive. In this work we relax this assumption discussing the effect of an input supplier with market power.

We present two possible settings: In the first, one of the option holders chooses the sharing rule, and the other chooses when to exercise the investment option. In the second, the two option holders choose the sharing rule using a Nash bargaining solution, and then one of them makes the exercise decision. In both settings we find that the presence of an upstream firm with market power implies an investment threshold that is $\beta /(\beta-1)$ times larger than what the extant literature anticipates:

$$
\frac{\hat{y}_{m}}{\hat{y}}=\frac{\bar{y}_{m}}{\bar{y}}=\frac{\beta}{\beta-1}>1
$$

This result underlines the importance of the nature of the input market: competitive or non-competitive. Unless the proper assumption is made, the investment thresholds presented in the literature can be greatly underestimated.

We also show that when the input market is non-competitive the results are not only quantitatively, but also qualitatively different. According to the literature a jointly held investment option can be exercised before, after, or exactly when the optimal investment threshold $y^{*}$ is reached depending on how the option holders interact and on the bargaining power distribution (Propositions 1 and 2). Here we show that these findings depend on the nature of the input market. In particular, we show that when the input supplier has market power the investment takes place always inefficiently late (Propositions 3 and 4). This means that the adverse effect that is attributed to the vertical distortion is so strong that it makes the 
game-theoretic framework downstream (non-cooperative versus Nash bargaining) of secondary importance.

Some extensions of this work could prove interesting: First, one can replicate this analysis for more decision-making frameworks. For instance, what if the timing decision is made first and the sharing rule is decided second (see the friendly merger case in Lambrecht 2004)? Second, it would be interesting to see how a different market structure upstream e.g., a duopoly would affect the overall analysis. Last, the timing of an investment can be a socially sensitive issue. For instance, an investment in production facilities for a new vaccine (Billette de Villemeur et al. 2014) or a carbon dioxide saving investment project (Lukas and Welling 2014) are expected to generate a flow of public benefits. Hence, a delay attributed to upstream market inefficiencies can prove to be costly in terms of social welfare. One direction in which this work could be extended is to model explicitly the impact of time discrepancies on the total social welfare, accounting for the fact that a policy maker can use investment stimuli, such as subsidies or tax cuts, to manipulate the behavior of potential investors and input manufacturers (see, e.g., Pennings 2000; and Maoz 2011).

Acknowledgements Open access funding provided by Università degli Studi di Brescia within the CRUICARE Agreement. I wish to thank Michele Moretto, Luca Di Corato, Richard Ruble, the Editor and two anonymous referees for their insightful comments and suggestions.

Open Access This article is licensed under a Creative Commons Attribution 4.0 International License, which permits use, sharing, adaptation, distribution and reproduction in any medium or format, as long as you give appropriate credit to the original author(s) and the source, provide a link to the Creative Commons licence, and indicate if changes were made. The images or other third party material in this article are included in the article's Creative Commons licence, unless indicated otherwise in a credit line to the material. If material is not included in the article's Creative Commons licence and your intended use is not permitted by statutory regulation or exceeds the permitted use, you will need to obtain permission directly from the copyright holder. To view a copy of this licence, visit http://creativecommons.org/ licenses/by/4.0/.

\section{References}

Banerjee, S., Güçbilmez, U., \& Pawlina, G. (2014). Optimal exercise of jointly held real options: A Nash bargaining approach with value diversion. European Journal of Operational Research, 239(2), $565-578$.

Benson, D., \& Ziedonis, R. H. (2009). Corporate venture capital as a window on new technologies: Implications for the performance of corporate investors when acquiring startups. Organization Science, 20(2), 329-351.

Billette de Villemeur, E., Ruble, R., \& Versaevel, B. (2014). Investment timing and vertical relationships. International Journal of Industrial Organization., 33, 110-123.

Chen, P. Y. (2012). The investment strategies for a dynamic supply chain under stochastic demands. International Journal of Production Economics., 139, 80-89.

Chesbrough, H., \& Schwartz, K. (2007). Innovating business models with co-development partnerships. Research-Technology Management., 50(1), 55-59.

Cvitanić, J., Radas, S., \& Šikić, H. (2011). Co-development ventures: Optimal time of entry and profitsharing. Journal of Economic Dynamics and Control, 35(10), 1710-1730.

Dixit, A. (1992). Investment and hysteresis. The Journal of Economic Perspectives, 6(1), 107-132.

Dixit, A., \& Pindyck, R. S. (1994). Investment under uncertainty. Princeton: Princeton University Press. 
Dixit, A., Pindyck, R. S., \& Sødal, S. (1999). A markup interpretation of optimal investment rules. Economic Journal, 109(455), 179-189.

Dushnitsky, G., \& Lenox, M. J. (2005a). When do incumbents learn from entrepreneurial ventures? Corporate venture capital and investing firm innovation rates. Research Policy, 34, 615-639.

Dushnitsky, G., \& Lenox, M. J. (2005b). When do firms undertake R\&D by investing in new ventures? Strategic Management Journal, 26(10), 947-965.

Folta, T. B., \& Miller, K. D. (2002). Real options in equity partnerships. Strategic Management Journal, 23, 77-88.

Gong, B. (2018). The shale technical revolution-cheer or fear? Impact analysis on efficiency in the global oilfield service market. Energy Policy, 112, 162-172.

Guiso, L., \& Parigi, G. (1999). Investment and demand uncertainty. Quarterly Journal of Economics, $114,185-227$.

Jørgensen, S., Kort, P. M., \& Dockner, E. J. (2006). Venture capital financed investments in intellectual capital. Journal of Economic Dynamics and Control, 30(11), 2339-2361.

Kogut, B. (1991). Joint ventures and the option to expand and acquire. Management Science, 37, 19-33.

Lambrecht, B. M. (2004). The timing and terms of mergers motivated by economies of scale. Journal of Financial Economics, 72(1), 41-62.

Leahy, J., \& Whited, T. (1996). The effect of uncertainty on investment: Some stylized facts. Journal of Money, Credit and Banking, 28(1), 64-83.

Li, J., Dhanaraj, C., \& Shockley, R. L. (2008). Joint venture evolution: Extending the real options approach. Managerial and Decision Economics, 29, 317-336.

Lukas, E., Mölls, S., \& Welling, A. (2016). Venture capital, staged financing and optimal funding policies under uncertainty. European Journal of Operational Research, 250(1), 305-313.

Lukas, E., \& Welling, A. (2014). Investment timing and eco(nomic)-efficiency of climate-friendly investments in supply chains. European Journal of Operational Research, 233(2), 448-457.

Maoz, Y. D. (2011). Tax, Stimuli of investment and firm value. Metroeconomica, 62, 171-174.

Martin, S. (1994). Private and social incentives to form R\&D joint ventures. Review of Industrial Organization, 9, 157-171.

McDonald, R., \& Siegel, D. (1986). The value of waiting to invest. Quarterly Journal of Economics, 101(4), 707-728.

McGrath, R. G., \& Nerkar, A. (2004). Real options reasoning and a new look at the R\&D investment strategies of pharmaceutical firms. Strategic Management Journal, 25, 1-21.

O’Brien, J. P., Folta, T. B., \& Johnson, D. R. (2003). A real options perspective on entrepreneurial entry in the face of uncertainty. Managerial and Decision Economics, 24, 515-533.

Pennings, E. (2000). Taxes and the stimuli of investment. European Economic Review, 44, 383-391.

Pennings, E. (2017). Real options with ex-post division of the surplus. Journal of Banking and Finance, 81, 200-206.

Pillai, U., \& McLaughlin, J. (2013). A model of competition in the solar panel industry. Energy Economics, 40, 32-39.

Quinn, J. B. (2000). Outsourcing innovation: The new engine of growth. Sloan Management Review, 41, $13-28$.

Reuer, J. J., \& Tong, T. W. (2007). Corporate investments and growth options. Managerial and Decision Economics, 28, 863-877.

Rothwell, G. (2009). Market power in uranium enrichment. Science and Global Security, 17(2-3), 132-154.

Scott, J. T. (1996). Environmental research joint ventures among manufacturers. Review of Industrial Organization, 11, 655-679.

Smit, H. T. J., \& Trigeorgis, L. (2006). Real options and games: competition, alliances and other applications of valuation and strategy. Review of Financial Economics., 15, 95-112.

Tong, T. W., \& Li, Y. (2011). Real options and investment mode: Evidence from corporate venture capital and acquisition. Organization Science, 22(3), 659-674.

van de Vrande, V. J. A., \& Vanhaverbeke, W. (2013). How prior corporate venture capital investments shape technological alliances: A real options approach. Entrepreneurship Theory and Practice, 37(5), 1019-1043.

Publisher's Note Springer Nature remains neutral with regard to jurisdictional claims in published maps and institutional affiliations. 